\title{
COMPARATIVE ANALYSIS BETWEEN DETERMINISTIC AND SYSTEMIC MANAGEMENT APPROACH FOR IMPROVED EFFECTIVENESS IN Public InVEstment In Peru
}

\author{
José Carlos Machicao ${ }^{1}$ and Yanina Hilario ${ }^{2}$ \\ ${ }^{1}$ Applied Artificial Intelligence Engineer, GestioDinámica, Lima, Peru \\ ${ }^{2}$ Independent Consultant and Researcher, GestioDinámica, Lima, Peru
}

\begin{abstract}
Public investment effectiveness in Peru remains low for decades, even with investment growth and technical quality improvement. Management approach is often considered as fixed and is not subject to study or change. This analysis goes deep in understanding how is the current public investment management approach, and compares it with deterministic and systemic approaches, concluding with a precise characterization and generating an improvement agenda in order to suggest changes that increase effectiveness and therefore contribute to a better quality of life of the population in Peru.
\end{abstract}

\section{KEYWORDS}

System Thinking, Public Investment, Effectiveness, Government, Management Approach

\section{INTRODUCTION}

Every organization, including any State, aims to fulfil achievements. In order to do this, they implement actions. An organization that "effectively" reaches its achievements through its actions is recognized as an effective organization [1]. The concept of effectiveness is so critical that it was used to create the concept of management, and helped to define the original meaning of management, as a discipline that increases, beyond the technique, the probability of increasing the organizational effectiveness [2].

The initial concept of organizational management incorporates both the management of resources and strategies to optimize the complete management of the organization, as well as its environment, as far as possible. In the beginning, management was understood as a more or less stable cycle, which maintained the balance between economic success and technical success, with the available resources, assuming a rather stable environment [3]. Over time, the concept of stability, strongly present these definitions, was diluted by the evidence of how the environment of organizations is far from being stable [4], in addition to understanding management as an extremely complex instrument, which more beyond its coverage in strategic and operational issues, it covers above all its human nature, and with it includes all the cultural complexity [5].

From these reflections, and subsequent increasing acceptance of diverse approaches in most organizations, management is no longer understood as only focusing on the technical-economic equilibrium, which often took the rest of the issues as accessory variables to obtain achievements. 
Operations Research and Applications: An International Journal (ORAJ), Vol.6, No.1/2, May 2019

Rather, the approaches that understand that the study of the behaviour of reality is a priority before making decisions, increases its acceptance.

Consequently, effectiveness takes on a new meaning. It ceases to be the ability to obtain what is wanted and becomes the ability to achieve those achievements that have already been proven possible in the middle of real scenarios, taking into account their behaviours not necessarily controllable, which allows distinguishing two "extreme" approaches; more and more precise in its definition:

- The deterministic approach: one that affirms that management is effective when having conceived an achievement that bets to obtain, develops strategies and operations that optimize the probability of obtaining it [1].

- The systemic approach: the one that affirms that management is effective when it studies in advance the complex behaviour of the systems that surround organizations, in order to delimit what achievements are possible, and within this margin, proposes a more attainable achievement [5].

What this study proposes is to evaluate how close is the current management of public investment in Peru, identifying which aspects could be improved in the short and medium term.

To do this, first estimate how effective is the management of public investment, then describe how it operates the management of public investment in Peru, taking into account that there is no specific functional system for this item [6], then describes the deterministic and systemic approaches in a common language in order to make them comparable, compares the management operation of public investment with the two reference approaches, to finally identify potential improvements in said operation.

\section{Measurement Of Public Investment Effectiveness In Peru}

Between the years 2001 and 2017, Peru has increased its gross domestic product (GDP) per capita from 2.0 thousand to 6.2 thousand US\$ [7]. The human development index (HDI) has also increased from 0.71 to 0.75 [8]. What is striking is the proportion of the increase in each case. While in the case of GDP has tripled, in the case of the HDI the increase is 5.6\%. In other words, this would mean that an average citizen has tripled their productive capacity, but has only slightly increased their quality of life.

Additional precision can be found in public investment information, which in the same period grew from approximately 12 to 44 billion US \$ [9], denoting a multiplication of 3.75 times in the same period. Undoubtedly, it must be presumed that there are many factors that can influence this disproportion; however, it is evident that it is notorious, not only evident in macroeconomic figures of the country, but also evident in the entire Latin American region [10]. The World Bank defines an indicator of government effectiveness as "the perception of the quality of public services, the quality of the civil service and the degree of its independence from political pressures, the quality of the formulation and implementation of policies, and the credibility of the government's commitment to such policies." Under this index, Peru remains below -0.1 during the entire period from 2001 to 2017 [11, 12].

Since this evidence of ineffectiveness of State actions is not new, initiatives to generate efficiency have been diverse. Some initiatives originated in international organizations and others in a national scope. From the international level, the creation of the Management for Development Results (Management for Development Results, MfDR) concept of the Inter-American 
Development Bank $[13,14]$, or at the national level in Peru, the attempt to gather in a single environment available for consultation through the site called "Resulta", publishing data linked to the indicators of budget programs by the Ministry of Economy and Finance (MEF) in Peru [15].

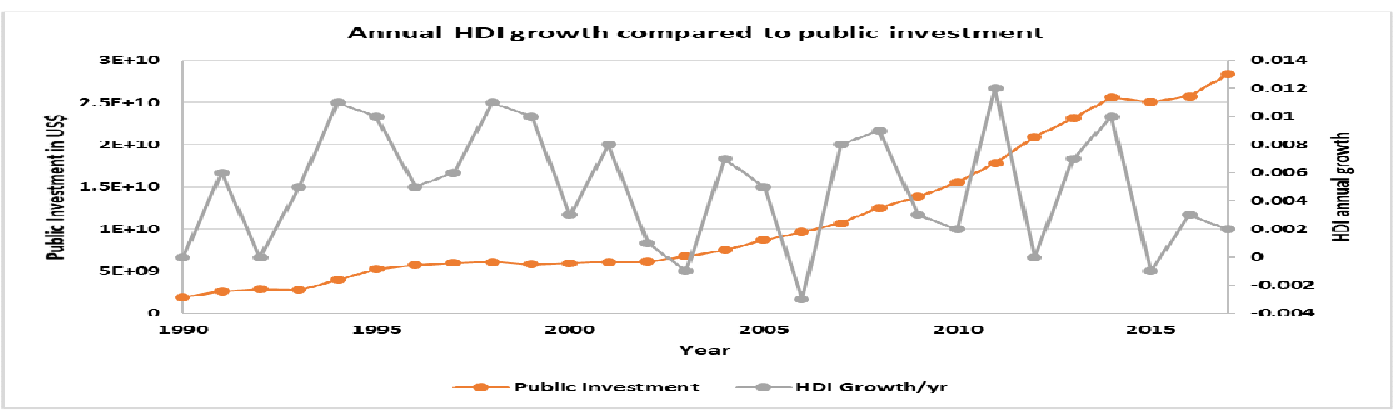

Figure 1. Annual HDI Growth compared to Public Investment in Peru, between 1990 and 2017. Source: World Bank. Elaborated by the authors.

In general, government reactions to low effectiveness are of a different nature. In Peru, the bestknown reactions are $[16,17]$ :

- A better articulation between plans and operations

- Incentives for budget execution

- Budget increase

- Increase in the professional quality of executors

- Increase in salaries for policy makers

- Supervision of the quality of the products

- Supervision of the alignment with long-term plans, such as sectoral plans, or regional and local development plans.

Although all these measures may have had a positive effect on the increase in effectiveness, they have been frequently applied throughout the study period (2001-2017), and as shown before, effectiveness remained low.

\section{Definition Of The Reference Management Approaches And A COMMON LANGUAgE For COMPARISON}

Literature review is performed to record the most precise definitions of management approaches in order to make them comparable, and then generate an articulated set of criteria that, in addition to making them comparable to the chosen approaches (deterministic and systemic), allow us to characterize the current public investment management approach.

Two aspects are taken into account to complete the scope of this review. One addresses the need to characterize two very representative management approach or models describing the sequence or decisions, and the other is to identify the influence of each approach in effectiveness.

\subsection{The Deterministic Management-Approach}

The First Industrial Revolution highlighted the scientific management approach that had begun with Ford and that Taylor was able to propose a management definition in a more academic way [3]. The approach basically said that no matter how perfect the technique used to manufacture a 
product; it was not possible to multiply the production capacity of a particular team if the scientific management was not applied. In other words, an organization without management had a more limited production capacity than an organization that applied management. From this historical point, the Second and Third Industrial Revolution, did not take long to (i) make the machine relevant to the operator and (ii) then the knowledge and information above the machine, respectively [18]. Although management quickly adapted to the industrial revolutions of the 1800-2000s, probably due to an aspect of conceptual security, the practitioners of management, both strategic and operational, kept the intuition of the "machine" as the centre of attention surprisingly persistent. organizational system [19].

Determinism, although already influenced by the recognition of complexity in reality and in the actions of organizations, did not stop considering as a management role trying to stabilize the systems to make them predictable, for which concepts such as standardization are generated and alignment [20]. In other words, the reaction of strategic and operational management to the complexity and dynamism of the real variables, both external and internal in the corporation, was clearly to try to make them less complex and less dynamic.

\subsection{The Systemic Management-Approach}

System dynamics broke into the world of management, and curiously with greater intensity in the management of the governments of the countries, calling attention to the limits of economic growth, stating that growth cannot be infinite because it is systemically conditioned to factors that interact in a complex way among them $[4,5]$.

The increasing verification of the impossibility of freezing the variables, to give rise to the acceptance of volatile, uncertain, complex and ambiguous variables (adopting the acronym VUCA by the abbreviations in English) took force in the management. The message was becoming clearer, avoiding the simplification of complex reality, and instead learning to manage it as such [19].

System dynamics is consolidated as a useful tool for the design of policies from the 1980s to the present, becoming useful and recognized for both corporate management [21] and public [22]. The practice of systems dynamics opens up the possibility of modelling reality with a different logic to, for example, econometrics, and instead of proposing modelling as the detection of the influence of a set of variables on an output one, understands rather the behaviour of several variables among themselves, as part of a complex system.

Nowadays, the systemic approach, understood as the knowledge and awareness about the behaviours rather than fixed variables, has managed to provide modelling with other additional tools, such as automatic computational learning and neural networks, thanks to a notable increase in computational capacity.

Using the previous archetypes of determinism, the influence of the systemic approach in management is not only about making the corporate "machine" faster or more automatic based on programming, but the joint system of machines and human beings reflects an understandable behaviour [19].

\subsection{A Common Language To Facilitate Comparative Analysis}

Based on the exploration described in sections 3.1 and 3.2, it is understood that in general, the State has the responsibility of the citizens to make decisions and then implement actions that 
guarantee an increase in the level of quality of life. Given this final impact sought and these actions implemented, it can be defined that, according to the space in which decisions are made, there are four different performance fields: final impact, action implementation, action design, and public authority. The definition of each one is shown in Table 1.

Table 1. Definition of Public Investment Performance Fields

\begin{tabular}{|l|l|}
\hline $\begin{array}{c}\text { Performance } \\
\text { Field }\end{array}$ & \multicolumn{1}{c|}{ Definition of Performance Field } \\
\hline Final Impact & $\begin{array}{l}\text { Impact performance field is the space in which the concrete benefit is } \\
\text { deployed. The benefit arrives to the beneficiaries. For instance, if health } \\
\text { recovery is delivered to citizens who suffered the effects of an epidemy. }\end{array}$ \\
\hline $\begin{array}{l}\text { Action } \\
\text { Implementation }\end{array}$ & $\begin{array}{l}\text { Actions are deployed in the implementation performance field. } \\
\text { Operational parameters including infrastructure and human resources } \\
\text { deployment are defined in this field. For instance, where direct medical } \\
\text { assistance is provided. }\end{array}$ \\
\hline Action Design & $\begin{array}{l}\text { Technical conception, modelling and design are defined in the action } \\
\text { design performance field. For instance, the technologies or kind of } \\
\text { treatment is defined here. }\end{array}$ \\
\hline $\begin{array}{l}\text { Public } \\
\text { Authorization }\end{array}$ & $\begin{array}{l}\text { Where political decisions are taken. Local or national government } \\
\text { agencies are involved through their political authorities. }\end{array}$ \\
\hline
\end{tabular}

\subsection{The Influence Of The Management Approach In Effectiveness}

As stated before, effectiveness is the degree of success of the whole set of actions in order to achieve some conditions. Within the public sector these conditions are closely related to population quality of life in all aspects that nations pursue.

From the technical point of view, effectiveness can be measured by the degree of coverage of aspects of quality of life for the whole population or a specific segment focused to deliver benefits. A very common idea is that management approach has no relevant influence in effectiveness. In other words, the cause of effectiveness is often more understood as aspects related to the capacity of action implementation and technical quality. For instance, if the investment seeks to improve primary school students learning capacity, it is rare to find questions as "what information is important to register first" and it is easier to find questions as "how we can make more textbooks to arrive early in the year".

Given certain condition of a segment of the population which needs to be improved, a sequence of consequences is described for each representative approach.

- If the deterministic approach is used, the hypothesis of how much impact can be achieved is usually blind, because the deterministic approach does not ask how the context behaves, but what it needs to be done. Afterwards, the decisions about the action design and implementation follow the hypothesis, even when it can be wrong. Consequently, when the impact is deployed, there are a lot of surprises in the impact field because the implementation and benefit realisation is the first stage in which the government can notice the distance between the behaviour of the context and the hypothesis. It is understandable that in real governments, particularly if there is lack of capacities and budget, the hypothesis simplification is a common resource in order to decrease the modelling budget.

- When systemic approach is used, the priority of dynamic information is very clear. It is compulsory for this approach to begin within the impact field, trying to understand behaviours. This step increases the reliability of the information. Often, information is not simplified at this stage. On the contrary, complexity and uncertainty are accepted. The 
systemic approach does not reduce the will to increase complex knowledge. This step feeds the complete decision process with high quality information. It is not based on simplified hypothesis. When enough information is gathered, the simulation of action implementation is easier and is not neglected. Pilot interventions are common at this stage and enrich the data. Action design increases the quality because of the enriched information and decisions can be improved. Also, in the authority field, political decision makers are better informed and tend to take better decisions.

\section{Description Of Current Public Investment Management APPROACH IN PERU}

In Peru, public management strategy that leads the performance of public investment is the Budget for Results (PpR, by its name in Spanish), which allows linking the allocation of budgetary resources goods and services (called "products") and results in favour of the population , so that these can be measurable PpR contributes with the improvement of the quality of the public cost when propitiate that the entities of the State do: (i) efficient and effective use of the public resources, prioritizing the public expense that, according to the evidence, contribute to the achievement of results linked to the welfare of the population, (ii) make better decisions in budgetary and management matters, with results in favour of the population. The PpR is implemented through four instruments: (i) budget programs, (ii) a system for monitoring budget programs, (iii) independent evaluations, which are studies that analyse the suitability of budget programs, and (iv) management incentives, which are specific benefits that executors receive for implementing budget programs more appropriately [15, 16, 23]

Table 2. Current Public Investment Management Approach in Peru by Public Investment Performance Fields

\begin{tabular}{|l|l|}
\hline \multicolumn{1}{|c|}{$\begin{array}{c}\text { Performance } \\
\text { Field }\end{array}$} & \multicolumn{1}{c|}{$\begin{array}{c}\text { Current Public Investment Management Approach by Performance } \\
\text { Field in Peru }\end{array}$} \\
\hline Final Impact & $\begin{array}{l}\text { Define results linked to changes that allow solving problems that affect } \\
\text { the population and generate the commitment to achieve them } \\
\text { Evaluate if the results are being achieved in favour of the population }\end{array}$ \\
\hline $\begin{array}{l}\text { Action } \\
\text { Implementation }\end{array}$ & $\begin{array}{l}\text { Determine those responsible for the achievement of the results, in the } \\
\text { implementation of the PfR instruments and in the accountability of } \\
\text { public expenditure } \\
\text { Introduce incentives to encourage public entities to work towards } \\
\text { achieving results }\end{array}$ \\
\hline Action Design & $\begin{array}{l}\text { Budgeting products (goods and services) that affect the achievement of } \\
\text { results }\end{array}$ \\
\hline $\begin{array}{l}\text { Establish mechanisms to generate information about the products } \\
\text { (goods and services), the results and the management carried out to } \\
\text { achieve them }\end{array}$ \\
Public \\
Authorization & $\begin{array}{l}\text { Use the information to decide on what and how public resources will } \\
\text { be spent, as well as for accountability }\end{array}$ \\
\hline $\begin{array}{l}\text { In Peru, Regional and Local Governments have the main authority to } \\
\text { decide "what to do". There are official and formal documents which } \\
\text { contain the long-term goals for every territory, but in practice those are } \\
\text { often not updated with recent information. At a national level, the } \\
\text { Executive Power is the entity leading the multi-year planning and } \\
\text { establishing policies. }\end{array}$ \\
\hline
\end{tabular}


Throughout the budget process the Entities (central, regional or local government), program resources to products that benefit the population (public interventions such as the Budget Programs), contributing in the decision making during the budget allocation process because it allows to use the information generated about results, products and the cost of producing them, guaranteeing doing so with transparency towards entities and citizens within the framework of accountability of public expenditure [13].

\section{Comparative Analysis Between The Current Public Investment Management ApProach AND Referential APPROACHES}

Deterministic and systemic management approaches are considered referential in order to describe and characterized the current approach in Peru. It is assumed that the sequence of steps within each approach moves around the four performance fields defined before. One way of presenting the sequence followed by both referential approaches is the distribution of the four fields in a plane, so that it is possible to plot the trajectories of the steps followed in both cases.

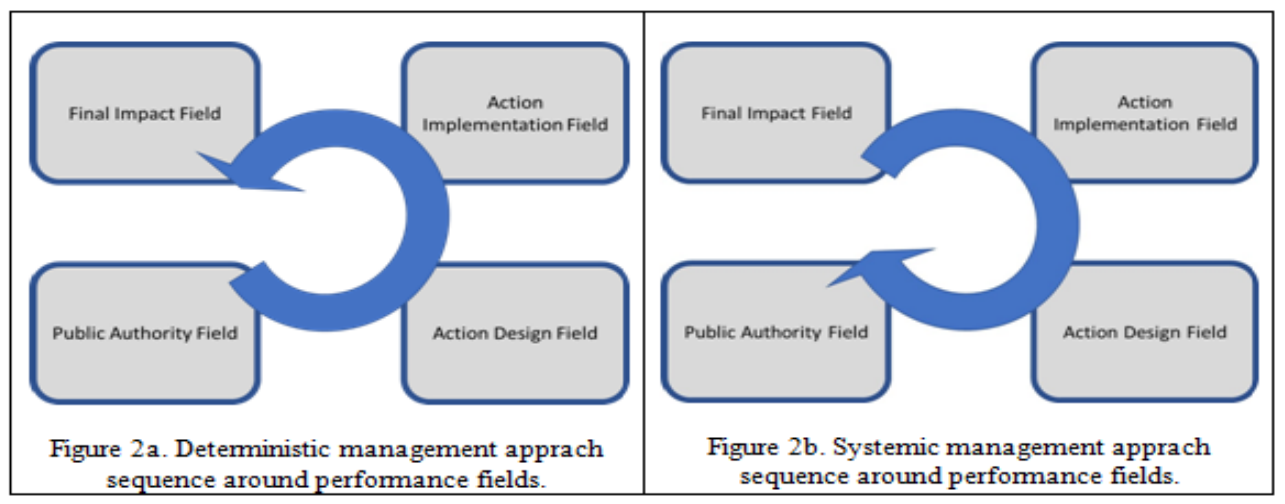

Figure 2. Management approaches diagram for deterministic and systemic approaches, around performance fields. Elaborated by the authors.

While the systemic approach (see Fig. 2a) takes as initial reference the reality of the environment of the impact, studying it, the deterministic approach (see Fig. 2b) starts from a hypothesis formulated without taking into account the knowledge of the reality of the impact performance field.

When the current approach in Peru is analysed, the start is identified it two different fields. It is true that Peruvian approach studies the impact field first, but only as a source of estimation of certain parameter that after its register remain fixed [13]. The purpose of collecting information is not to have a clear understanding of how the contexts behaves, but to inform the political authority in order to facilitate the decision-making process (see Fig. 3).

The following steps are mainly deterministic. The highest weight of will remains in the political authority, even when technical parameters have to be decided. Often, the political authority is so powerful within the approach that the original decision remains the same even when evidence from reality come from the field, particularly in the action implementation field. This idea is contained in formal legislation of the approach [13, 14, 20]. 


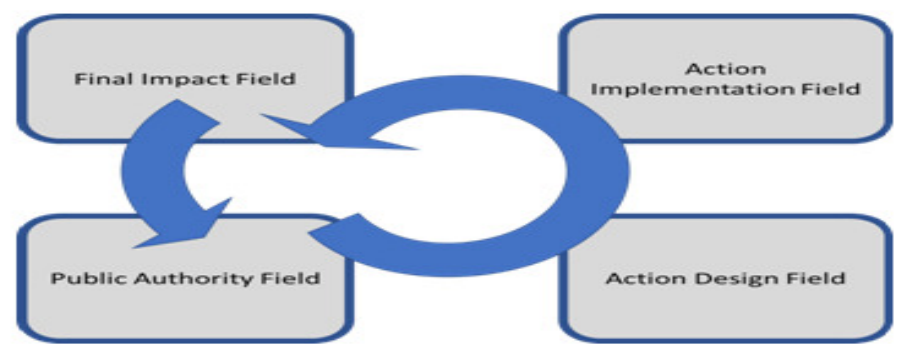

Figure 3. Current public investment management approach diagram among the performance fields. Elaborated by the authors.

The importance of characterizing the schematization of the Peruvian real public investment management approach is supported in the need to make evident the great influence of the management approach in effectiveness. In Section 3.4, the importance of the influence of the management approach was highlighted. The consequence can be noticed when the effectiveness is evaluated.

- The effectiveness of the deterministic approach is severely reduced by the sequence of steps. The lack of information when designing and implementing actions leads to frequent failures when the dissociation between real conditions and hypothesis appears.

- The effectiveness of the systemic approach is highly increase because of the knowledge available when designing or implementing actions. This leads to highly reliable and adaptable actions, without fixation of parameters but information about dynamic behaviours.

- For the Peruvian case, it is evident that this approach is much closer to the deterministic approach. Information about increasing budgets during the implementation of public investment actions, such as budget programs and interventions support the idea that the real budgets are wrongly designed because of the excessive simplification of information and knowledge or the use of simplified hypothesis as a common practice to design actions.

\section{Conclusions}

The study of the management approach demonstrated to be useful because it can be said that, even with a very limited and conceptual analysis, effectiveness not only depends on technical performance or the volume of investment, but importantly in the sequence of decisions, which in time is dependent on the management approach.

It was demonstrated at certain big picture level that the management approach of the public sector has a significant influence on the capacity to achieve impacts. It was possible to schematise management approaches, both referential as deterministic and systemic, and real approaches as the Peruvian current public investment management approach. This schematisation is clearly useful to improve the capacity to make evident consequences as important as the budget efficiency or the reliability of design for public actions.

System thinking and therefore systemic management approach, demonstrated to be largely positive to influence the whole decision-making sequence for public investment in Peru. Since Peruvian public investment management approach is mainly deterministic, several improvements can be done such as: (i) increasing the volume, dynamism and complexity of the information collected before the design of public actions, (ii) increasing the use of complex models under the 
Operations Research and Applications: An International Journal (ORAJ), Vol.6, No.1/2, May 2019

system thinking management approach in order to improve design of public actions, and (iii) the ability to implement actions with more complex and dynamic information, using the tools and sequence of systemic approach can improve the impact achievement. Therefore, improving impact, effectiveness will increase systemically.

\section{REFERENCES}

[1] Drucker, P.F. (1974). Management: Tasks, responsibilities and practice. Routledge.

[2] Mintzberg, H; Ahlstrand, B; Lampel, J. (1998). Strategy Safari: A guided tour through the wilds of strategic management.

[3] Taylor, F.W. (1919). The principles of scientific management. Harper \& Brothers Publishers.

[4] Meadows, D; Meadows, D; Randers, J; Behrens, W. (1970). Limits to Growth. Universe Bo

[5] Meadows, D. (2008). Thinking in Systems: A primer. Chelsea Green Publishing.

[6] Congreso de la República del Perú. (2007). Ley No. 29158. Ley Orgánica del Poder Ejecutivo. Estado Peruano.

[7] The World Bank. (2019). DataBank. Extracted from website: http://databank.worldbank.org. World Bank.

[8] United Nations Development Program (UNDP). (2019). Human Development Reports. Extracted from: http://hdr.undp.org/

[9] Census of Economic Information Centre. Peruvian Government Expenditure Historical Data. https://www.ceicdata.com

[10] McCutchan, A. (2010). Understanding the innefficacy of structural adjustment programs in Latin America. School of Economics and Management, Lund University.

[11] The World Bank. (2019). GovData360. Website: https://govdata360.worldbank.org. World Bank.

[12] Thorn, Kristian; Lyndrup, Mads. The quality of public expenditure: Challenges and solutions in results focused management in the public sector in Denmark. OECD.

[13] Kaufmann, J; Sanginés, M; García-Moreno, M. (2015). Building Effective Governments Achievements and Challenges for Results-Based Public Administration in Latin America and the Caribbean. IDB.

[14] Organization for Economic Co-operation and Development (OECD). (2001). Principles of Budgetary Governance. Extracted from: http://www.oecd.org/gov/budgeting

[15] Ministerio de Economía y Finananzas (MEF). (2019). Resulta: Indicadores de Desempeño de los Programas Presupuestales. https://apps4.mineco.gob.pe/resulta2 . Ministerio de Economía y Finananzas.

[16] Ministerio de Economía y Finanzas de Perú. (2019). Presupuesto por Resultados. Extraido de: https://www.mef.gob.pe/es/presupuesto-por-resultados/ique-es-ppr

[17] Ministerio de Economía y Finanzas de Perú. (2019). Preguntas Frecuentes sobre el Presupuesto por Resultados. Extraido de https://www.mef.gob.pe/contenidos/presu_publ/ppr/preg_frecuentes_ppr.pdf 
Operations Research and Applications: An International Journal (ORAJ), Vol.6, No.1/2, May 2019

[18] Rifkin, J. (2011). The Third Industrial Revolution: How Lateral Power Is Transforming Energy, the Economy, and the World St. Martin's Press, Political Science.

[19] Mack, O. et al. (2016). Managing in a VUCA World. Springer.

[20] Kaplan, R; Norton, D. (2006). Alignment: Using the Balanced Scorecard to Create Corporate Synergies. Harvard Buisness Press.

[21] Chong Chi, K. el al. (2009-03). Dynamics of the UK natural gas industry: System dynamics modelling and long-term energy policy analysis. Technological Forecasting and Social Change. Volume 76, Issue 3, Pages 339-357. Elsevier.

[22] Mutingi, M. et al. (2017-11). System dynamics approaches to energy policy modelling and simulation. Energy Procedia, Volume 141, Pages 532-539

[23] Gobierno del Perú. (2019). Presupuesto por Resultados. Extraido de: https://www.gob.pe/843presupuesto-por-resultados

\section{AUTHORS}

Jose C. Machicao is an engineer expert in complex modelling. Uses applied artificial intelligence to develop models for natural language processing and data analysis. Also uses system dynamics and network science for complex modelling specifically for management models. Holds a Master of Science in Energy from the University of Wales, United Kingdom, and a Licence as Mechanical Engineer from the Pontificia Universidad Católica del Perú. ORCID 0000-0001-8527-7663.

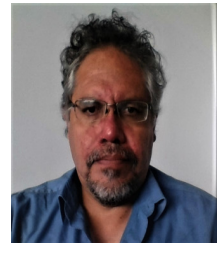

Yanina Hilario is a legal expert in public investment and public-private partnerships contracts. Has more than 15 years' experience working in the public sector in fields as transport, environment and social development, specifically as normative advisor. Experience developing administrative legal management tools. She holds a Law Degree from the Pontificia Universidad Católica del Perú.

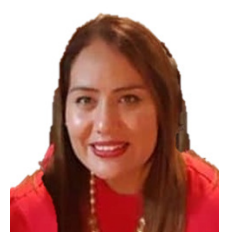

